\title{
Pain of Skin, CTCAE
}

National Cancer Institute

\section{Source}

National Cancer Institute. Pain of Skin, CT CAE. NCI Thesaurus. Code C143724.

A disorder characterized by a sensation of marked discomfort in the skin. 